\title{
A REVIEW ON COMPOSITE ACTIONS OF PLATE-REINFORCED COMPOSITE COUPLING BEAMS
}

\author{
Z.W. Shan and R.K.L. Su * \\ Department of Civil Engineering, The University of Hong Kong, Pokfulam Road, Hong Kong, PRC \\ *(Corresponding author: E-mail: klsu@hku.hk)
}

\section{A B S T R A C T}

Reinforced concrete (RC) shear walls are widely utilized to resist lateral and gravity loads in modern building designs. The adjacent wall piers are usually connected to the coupling beams. Severe earthquake and wind loads challenge the seismic and shear resistance of conventional reinforced concrete (RC) coupling beams respectively. Their shear and chord rotational capacities may not be able to prevent excessive loading and deformation. Therefore, a plate-reinforced composite (PRC) coupling beam has been developed with the aim to provide a practical and effective alternative that resists extreme loads in building designs. The PRC coupling beam comprises a vertically embedded steel plate that is framed into the wall piers for anchorage and spans across the RC beam. Shear studs are used to increase the composite interaction between the RC components and the embedded steel plate. In this paper, the composite actions between the RC components and the embeded steel plate are discussed. The factors that affect the shear strength and inelastic response of the PRC beams are elaborated. The findings in this paper can be used to enhance the understanding of practitioners on the load-transfer process and capability of PRC coupling beams.

\section{A R T I C L E H I S T O R Y}

$\begin{array}{ll}\text { Received: } & 25 \text { October } 2019 \\ \text { Revised: } & 24 \text { February } 2020 \\ \text { Accepted: } & 25 \text { February } 2020\end{array}$

Accepted: $\quad 25$ February 2020

\section{KE YWO R D S}

Coupling beams

steel composite structures

steel studs;

shear strength;

Inelastic response

\section{Copyright $\odot 2020$ by The Hong Kong Institute of Steel Construction. All rights reserved.}

\section{Introduction}

In contemporary highrise buildings, coupled shear walls are commonly employed to resist lateral loads caused by wind and earthquake loads. Typical coupling beams that connect two wall piers together usually have small cross-section dimensions, short span and a low span-to-depth ratio. They are used to reduce flexural moments in coupled shear wall piers, reduce the lateral deflection of a tall building, and dissipate energy during a severe earthquake. As one of the most critical members in reinforced concrete (RC) buildings, coupling beams need to have high shear capacity, deformability and energy dissipation capacity. However, conventional RC coupling beams (as shown in Fig. 1(a)) are prone to brittle failure under severe earthquake loading. Diagonal cracks may form when the beam is under-reinforced in shear. On the other hand, even when there is sufficient shear reinforcement, sliding failure could not be avioded at the beam-wall joints. Therefore, conventional RC coupling beams have limited deformability and shear capacity [1-4]

For existing buildings, seismic strengthening of RC coupling beams [5-7] may be required. For new construction, different types of coupling beams as shown in Fig. 1 that have good hysteretic performance yet are practical for construction purposes can be adopted, including diagonally RC coupling beams [8-11], encased steel composite coupling beams [12-13], and composite coupling beams that are reinforced with steel plates [14] (plate-reinforced composite (PRC) coupling beams).

Diagonally RC coupling beams [8-11] are well known to have excellent energy dissipation capacity and deformability. However, their applicability is limited by constructability issues such as a large width $(>350 \mathrm{~mm})$ required to accommodate all reinforcements, the labour intensity of steel fixing and their ineffectiveness when the span-to-depth ratio is larger than two. Although the structural performance of the encased steel composite coupling beams developed by Harries et al. [13] is comparable to that of diagonally RC coupling beams, the wide flange steel members can interfere with the vertical and confinement reinforcement in the shear walls. Furthermore, the embedded steel members may block the sleeves that are required to run laterally through the beam as the service ducts.

Therefore, PRC coupling beams have been proposed to address the issues on the use of steel members and shear wall reinforcement; see Fig. 1(d). These beams comprise a steel plate which is embedded onto a conventional RC beam. Shear studs are provided to bond together the steel plate and the concrete. They are flexible in design, simple in construction and particularly suitable for slim floor systems with restrictive height limits. The embedment of a steel plate does not interrup the existing reinforcement details. Therefore, walls, slabs and coupling beam reinforcements can be seamlessly integrated together. The vertical arrangement of the steel plate allows concrete to be filled and compacted easily, so honeycomb defects can be avoided. In addition, the surrounding concrete can provide fire and lateral buckling resistance for the cast-in steel plate. (a)
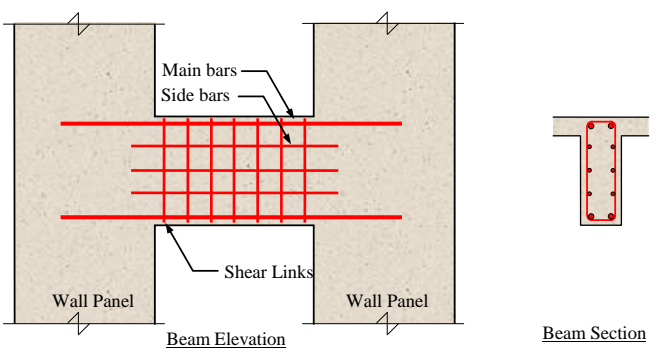

(b)

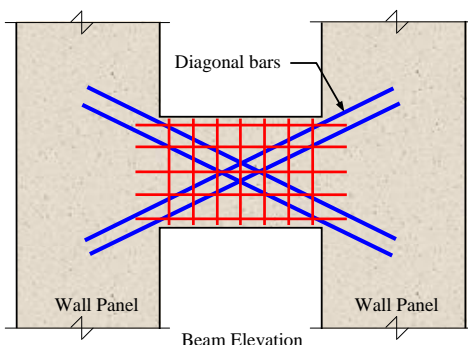

Beam Section

(c)
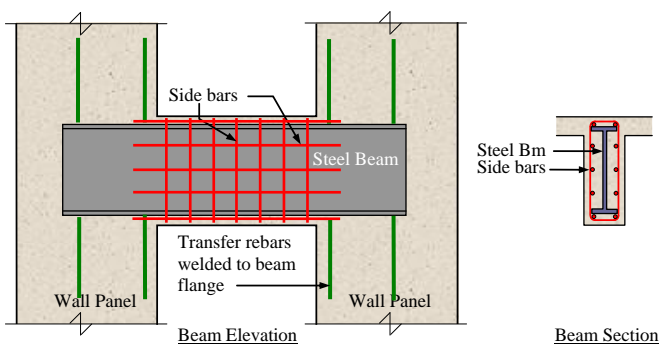

Beam Section

(d)
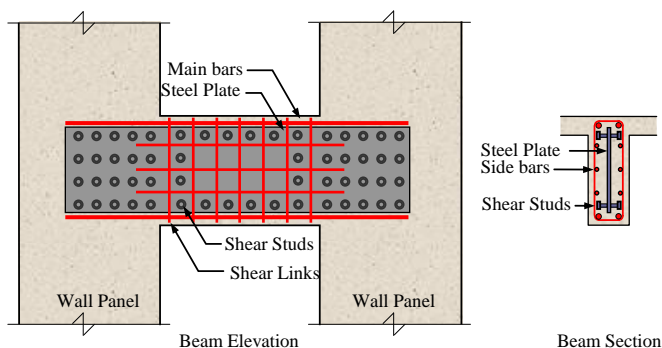

Fig. 1 Different types of coupling beams: (a) conventional RC, (b) diagonally RC, (c) encased steel composite, and (d) PRC coupling beams

A 2019 review of the structural performance and practical limitations of 
various types of coupling beams by Liao and Pimento [15] recently found that the PRC coupling beam can provide an $80 \%$ higher shear capacity and a wider applicable range of span-to-depth ratios than the diagonally reinforced concrete coupling beam. The PRC coupling beam also has better constructability than: steel coupling beams, encased steel composite coupling beams and diagonally reinforced coupling beams. This novel method provides an easy and practical design solution for coupling beams used in tall buildings that are over 50 stories in height to resist strong wind and earthquake forces.

Many experimental studies [14, 16-19] have been done to (i) investigate the effectiveness of PRC coupling beams in shear strength enhancement, (ii) examine the inelastic bahavior of PRC coupling beams under reverse cyclic loads, (iii) explore the role of shear studs during the interaction between the steel plate and RC component, and (iv) study the load distribution in the RC beam and steel plate. Furthermore, comprehensive non-linear finite element analyses [20-21] have been carried out to quantify the forces of shear stud in beam span and to establish the design model of wall anchorage system which includes (i) determination of axial force induced in the wall anchor, (ii) evaluation of optimum plate anchorage length in wall region, and (iii) determination of the moment from the vertical and horizontal bearing forces. Based on those studies, Su and Lam [22] proposed design guidelines for PRC coupling beams in accordance with British standards. Since then, this new design method has been adopted worldwide in the design of tall and super tall buildings; for instance, the Trump International Hotel Waikiki in Hawaii [23], Pacifica Honolulu in Hawaii [24], Tsubaki Tower in Guam, and other high-rise buildings in Bangkok, Thailand; Dubai, United Arab Emirates; and Florida, USA.

In this paper, the composite action between the steel plate and RC components which have not been systematically discussed in previous studies will be elaborated. The influence of shear stud arrangements on the shear strength and inelastic response of PRC coupling beams will be presented. The intention of this study is to inform building designers of the load transfer process and behaviour between steel plates and PRC coupling beams.

\section{Composite actions}

When a building with coupled shear walls is subjected to wind or seismic loads, the building will deflect with the load and the coupling beams will deform due to the rotation of the wall piers as shown in Fig. 2. When PRC coupling beams are used instead and a steel plate is embedded onto the wall piers by using shear connectors, the steel plate and the RC component will sustain a similar rotation demand at the ends of the coupling beams. Shear studs placed on the different wall regions primarily contribute to the composite action between the steel plate and RC component. Furthermore, the shear connectors that are placed along the beam span also contribute to the composite action. These composite actions which can greatly affect the strength and deformability of beams will be discussed in the following sections.

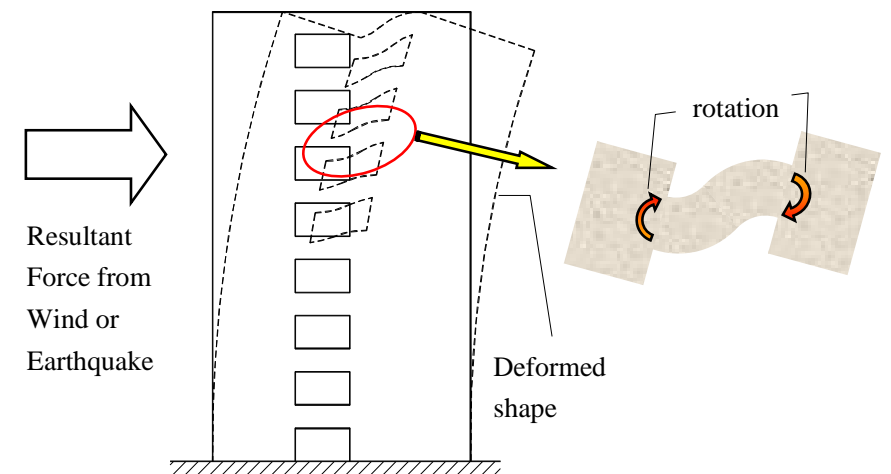

Coupled Shear Wall Structure $\quad$ Coupling Beam

Fig. 2 Wind or earthquake induced deformations on coupling beams

\subsection{Composite action along beam span}

Assuming that the steel plate has been properly installed on the wall piers, the embedded steel plate and RC component will sustain the same rotation at the beam-wall interface when the beam is subjected to bending. If shear studs along the beam span have not been installed, the strain profile of the RC component and steel plate will not match. The neutral axis of the steel plate and that of RC components will separate as illustrated in Fig. 3(a). Conversely, if a sufficient number of shear studs have been installed along the beam span, the separation of the two neutral axes will be reduced and the two strain profiles will be more similar, see Fig. 3(b). The changes in the strain profile will cause axial tensile deformation in the steel plate and axial compressive deformation is produced in the RC component. Such axial force induced along the steel plate has been revealed from a reverse cyclic load test by Lam et al. [17]. They added shear studs to the wall regions and along the beam span. The differences in the internal axial forces of the embedded steel plate at different load levels from the first load cycle up to the peak load is shown in Fig. 4. It can be seen that the plate is always under axial tension. The maximum axial force is obtained near the beam-wall interface, which decreases from the beam-wall joints to a minimum value at mid-span. The induced axial force is comparable to the shear load that is acting on the beam. This type of interaction should be considered in the flexural design of RC sections and the steel plate as well as in the anchoring design of steel plates.

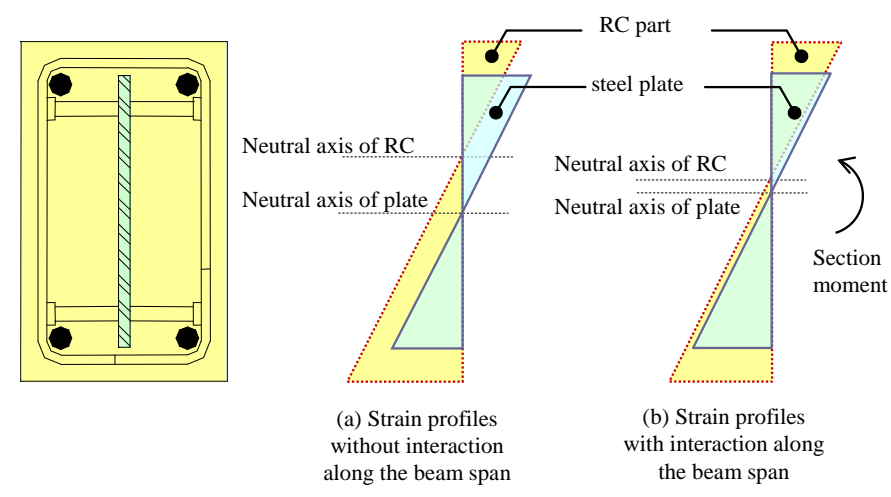

Fig. 3 Strain profiles of concrete and steel plates (a) without and (b) with interaction along the beam span
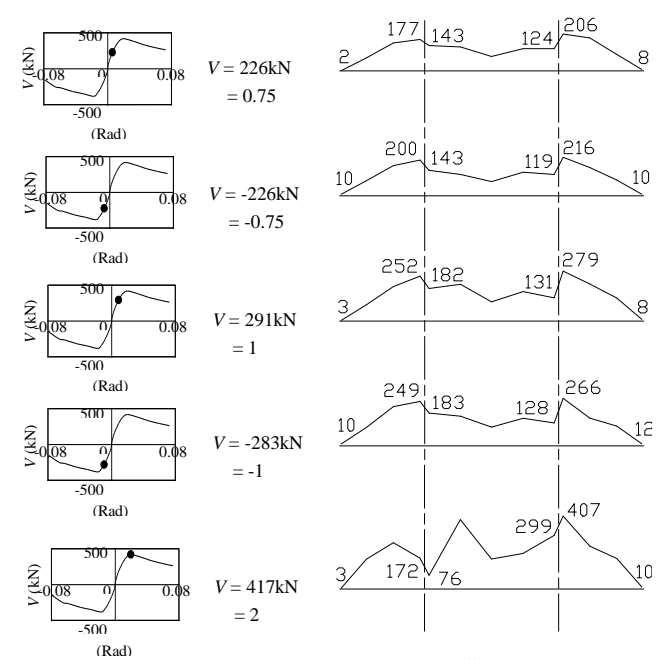

(Rad)

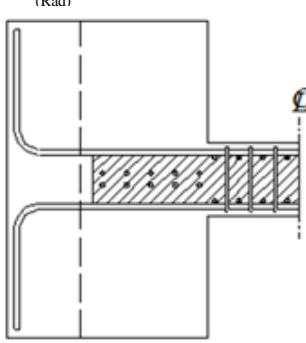

Beam-Wall Interface

E
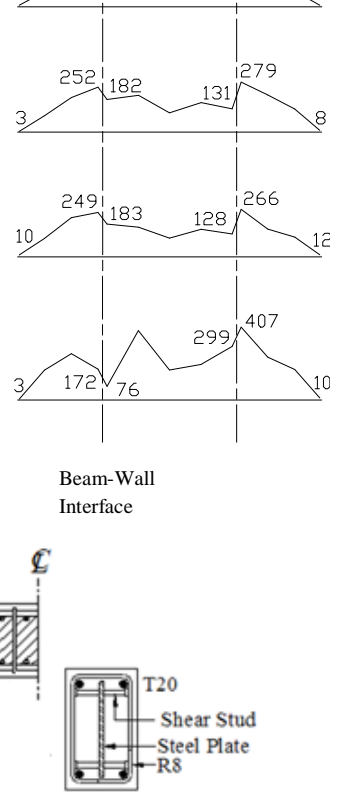

Fig. 4 Typical distribution of internal axial force on embedded steel plate [17]

Using a non-linear finite element method, Su et al. [20] determined the maximum axial force at beam-wall joints. Typical variations in the axial load in the ratio of the span-to-depth $(l / h)$ of the coupling beam and the thickness of the plate to the beam width ratio $\left(t_{\mathrm{p}} / b\right)$ are shown in Fig. 5 . In this figure, $F$ is the induced axial force and $V_{\mathrm{u}}$ is the design ultimate shear load. The results indicate that the induced axial load increases with an increase in the span-to-depth ratio of the coupling beam.

According to their numerical analysis, four functions of shear studs that are installed on the beam span as illustrated in Fig. 6 are observed and described below. 
(i) Forces in the vertical studs maintain the tension tie effect of the steel plate

Although shear is mainly developed on the steel plate on the wall anchors, approximately $15 \%$ to $30 \%$ of the design shear capacity of the PRC coupling beam is induced on the beam span near the beam-wall interface. Therefore, plate anchor should also be placed away from the beam-wall joint to transfer the plate shear force.

(ii) Vertical forces in the studs induce shear in the steel plate

The stud forces are meant to maintain tension tie action through the steel plate.. Tension tie action is similar to the strengthening provided by the shear stirrups.

\section{(iii) Horizontal forces in the studs apply moments on the steel plate}

The difference in curvature between the RC component and steel plate mobilise the shear connectors. Opposite horizontal forces are generated in the pairs of shear studs near the top and the bottom of steel plate, which induces bending moments on the steel plate and thus enhance the composite action between the plate and RC component.

(iv) Horizontal forces of studs that apply axial tension force on steel plate

These horizontal forces in shear studs are due to the shifting of the neutral axis of the RC component and embedded steel plate as described in the previous section.

In the light of the results from the comprehensive parametric study, design equations were proposed to predict the required shear connection forces associated with the aforementioned functions through a non-linear regression analysis [20].

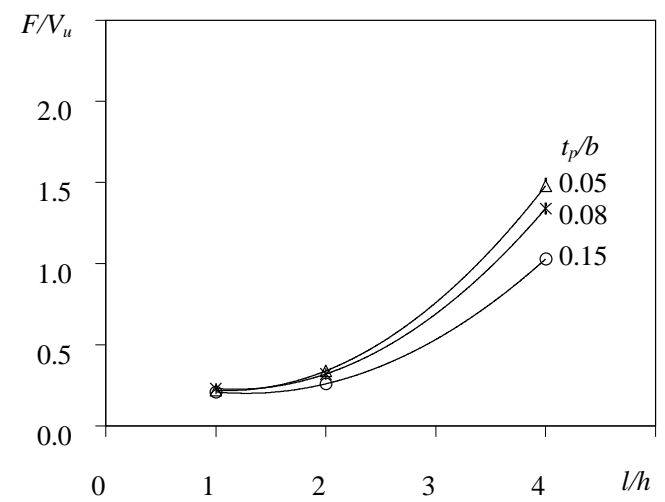

Fig. 5 Typical variations in the axial load of steel plate in the span-to-depth ratio of the coupling beam

\subsection{Composite action along wall anchor}

To ensure good composite interaction between the RC component and the embedded steel plate, the plate end should be fully fixed on the wall piers such that the plate and the wall pier sustain the same rotation at the beam-wall joint. To achieve this, the anchor of the plate resists all of the forces in the plate including the horizontal forces caused by the elongation of the RC component. The bearing force distributions at wall anchor of the embedded steel plate are shown in Fig. 7.

The bearing force distributions at the anchor of the plate actually depend on the anchorage load from the plate, arrangement of the shear studs, and embedment length of the plate $L_{\mathrm{a}}$. The embedment model proposed in Mattock and Gaafar [25] which is widely used for the design of encased steel composite coupling beams is not applicable to the plate anchor design of PRC coupling beams as the horizontal anchorage force and the moment resistance from the horizontal bearing forces have not been considered in their model.

Su et al. [20] and Lam et al. [21] used a non-linear finite element analysis with a uniform distribution of the shear studs in both the vertical and horizontal directions to derive the minimum anchorage length of the embedded steel plate and the moment resistance associated with the bearing force distribution in the horizontal and vertical directions. Their studies found that the minimum anchorage length for a steel plate depends on the span-to-depth ratio of the coupling beam. The anchor length-to-beam span ratio $\left(L_{\mathrm{a}} / l\right)$ decreases with an increase in the span-to-depth ratio $(l / h)$ of the beam. It has been indicated that when the $l / h$ ratio is 1,2 , or 4 , the corresponding $L_{a} / l$ ratio is $0.76,0.58$ and 0.4 , respectively. Furthermore, these two studies found that the contribution from the horizontal bearing force $\left(M_{1}\right)$ to the moment resistance decreases with an increase in the $L_{\mathrm{a}} / h_{\mathrm{p}}$ where $h_{\mathrm{p}}$ represents the emebeded steel plate depth. Conversely, the contribution of the vertical bearing force $\left(M_{2}\right)$ to the moment resistance increases with that of $L_{\mathrm{a}} / h_{\mathrm{p}}$.

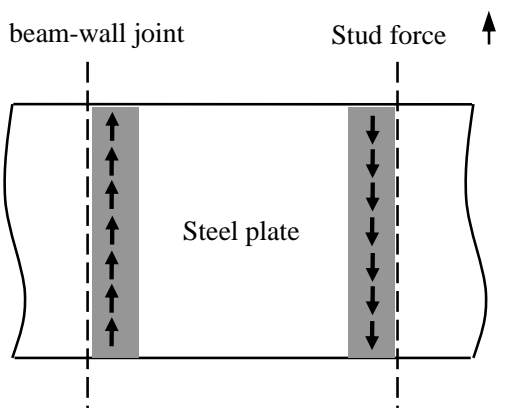

inducing plate shear force
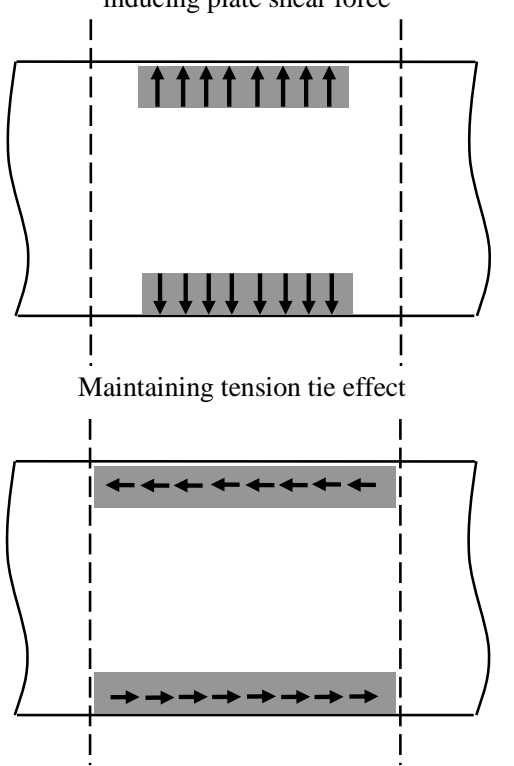

inducing plate bending moment

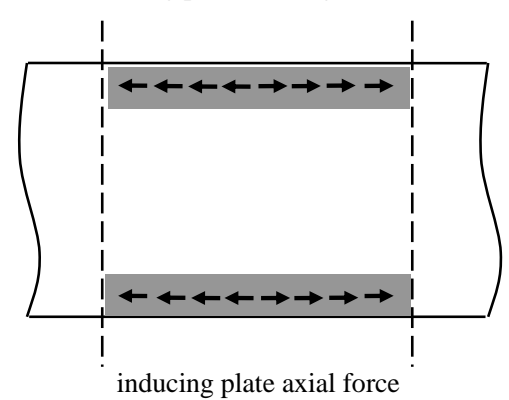

Fig. 6 Four basic functions of shear connectors in beam span

\section{Shear strength of PRC coupling beams}

Coupling beams with high shear capacity are often required when designing tall buildings with a coupled shear wall system to resist wind loading. The ultimate shear capacity of the PRC coupling beams is governed by the strength of the RC component, steel plate and wall piers for plate anchor together with the arrangements of shear connectors. An experimental study [18] on PRC coupling beams that comprise different arrangements of shear connectors in the wall and beam regions found that there should be sufficient shear connectors in the wall region to avoid anchorage bond slip of the plate. Poor anchorage of the plate to the wall region can inhibit the development of the full shear capacity of short PRC coupling beams. The shear studs that are installed on the beam span can only marginally improve the composite action between the emebeded steel plate and RC component and the shear strength of the PRC coupling beam.

When there is a large amount of composite action on the PRC coupling beam, a similar internal deformation of the steel plate and RC component is expected. To realise the full potential of the PRC coupling beam in resisting 
shear, yielding of the steel plate and longitudinal reinforcement should occur at the same time. Thus the strength of the steel plate should be similar to that of the longitudinal reinforcement. If a high yield steel is used for the longitudinal bars, high strength steel plates should also be used on the PRC coupling beams.

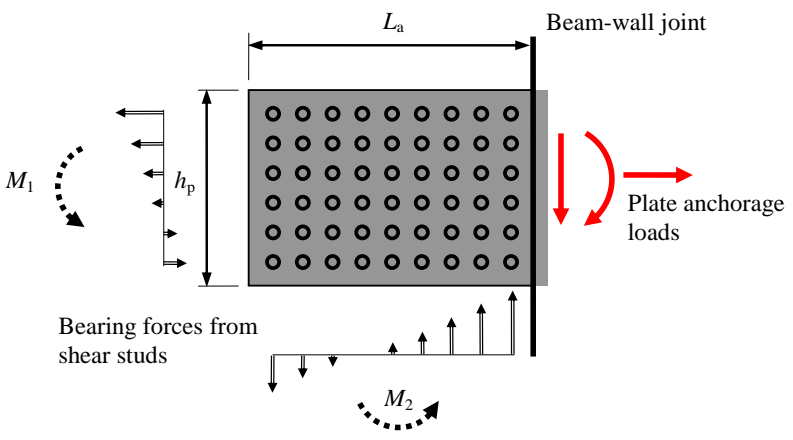

Fig. 7 Bearing force distributions at the plate anchor

An experimental study by Lam et al. [26] on PRC coupling beams demonstrated that the shear capacity of a PRC coupling beam (MPrc-2, with a plate area ratio of $4.4 \%$ ) can double in comparison to conventional $\mathrm{RC}$ coupling beams (MRc), see Table 1. In addition, the shear resistance of PRC coupling beams (SPrc-1 and SPrc-2) is around 30\% higher than that of the diagonally $\mathrm{RC}$ beam (SDRc) as shown in Table 1. It is possible to further increase the shear capacity of PRC coupling beams by adopting a thicker plate without the steel congestion problem faced by diagonally RC coupling beams. In the design guide of PRC coupling beams [22], the shear resistance from the steel plate is recommended to be limited to $45 \%$ of the total shear capacity.

As the shear loads sustained by the steel plate together with the RC component will eventually be transferred to the wall piers, the total shear capacity of the PRC coupling beam will also be limited by the load carrying capacity of the wall piers. Lam et al. [21] conducted a numerical parametric study, and recommended that the maximum shear stress $\left(V_{\mathrm{u}} / b d\right)$ of PRC coupling beams should not be more than $15 \mathrm{MPa}$. With a material safety factor of 1.25, the allowable design shear stress should be restricted to $v_{u}=V_{u} / b d \leq 1.5 \sqrt{f_{c u}} \leq 12 \mathrm{MPa}$.

\section{Inelastic performance of PRC coupling beams}

In designing RC coupled shear wall systems with seismic resistance, practitioners are often concerned about the inelastic response of the coupling beams, such as the ultimate rotation, ductility, hysteretic response, damping ratio, etc.

Lam et al. [17] conducted an experimental study on PRC coupling beams which applied a span-to-depth ratio of 2.5 under reverse cyclic loading. They fiund that shear connectors are necessary to increase the composite action between RC component and the plate, in order to obtain a good inelastic performance under large imposed deformations. Fig. 8 compares the hysteretic loops of the coupling beams with and without shear studs in the wall regions. In Unit MPrc-N with a plain plate, severe pinching can be observed in the load-rotation hysteretic curve after reaching the peak load. Unit MPrc-W with shear studs welded on its plate in the wall regions can maintain load-resistance of the beam even after serious cracking of the beam-wall joints. By comparing the hysteretic loops of the PRC coupling beams with and without shear studs along the beam span, Lam et al. [17] found that studs along the beam span would only slightly improve the inelastic response of PRC coupling beams. They showed that shear studs in the wall regions rather than along the beam span can effectively mitigate pinching in the inelastic hysteretic loops and improve the deformability, ductility and energy dissipation capacity of PRC coupling beams. It should be noted that the embedded steel plate can maintain continuous shear transfer in the beam-wall joints even after concrete cracking and loss of aggregate interlock. The embeded steel plate is vital for achieving a desirable inelastic performance.

The structural performance of PRC coupling beams with the same total longitudinal reinforcement ratio but different bar diameters was investigated by Lam et al. [16]; see Fig. 9(a). Their study found that the patterns of the cracking of these two beams are similar before reaching the peak loads, where shear cracks and small flexural cracks are observed at the plastic hinges and along the longitudinal reinforcing bars respectively. However, after reaching the peak load, bond-slip cracks began to be pre-dominant in the beam with larger diameter longitudinal reinforcement which did not initiate cracking in the centre of the beam throughout the tests. Very little bond-slip occurs in beams with smaller diameter longitudinal reinforcement, while flexural shear cracks continue to develop and propagate towards the centre of the beam, see Fig. 9(b). Thus, to avoid bond-slip failure under large deformations and fully utilize the potential capacity, a longitudinal bar size over $1 / 10$ of the smallest dimension of the beam is recommended.

In general, the rotation and ductility capacities of properly designed PRC coupling beams with a sufficient number of shear studs in the wall anchors could reach 0.04 rad and 4 respectively for beams. The equivalent elastic damping coefficient can be increased from around 5\% to $12 \%$ for a ductility factor that has increased from 1.0 to 4.0 .

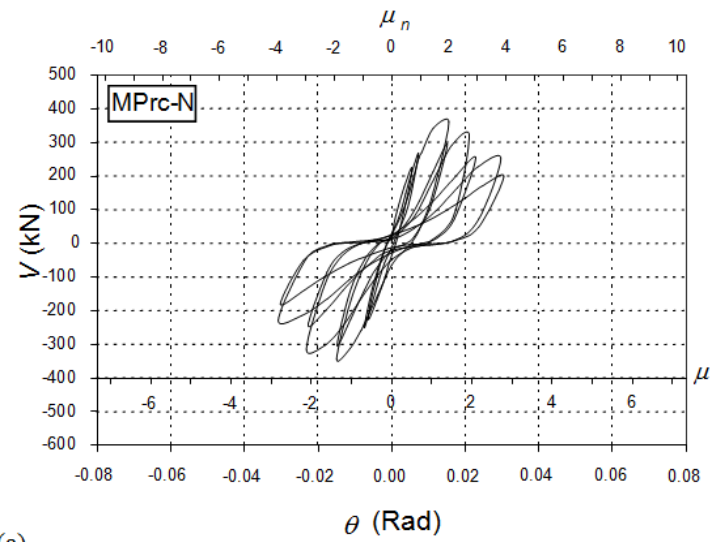

(a)

$\mu_{n}$

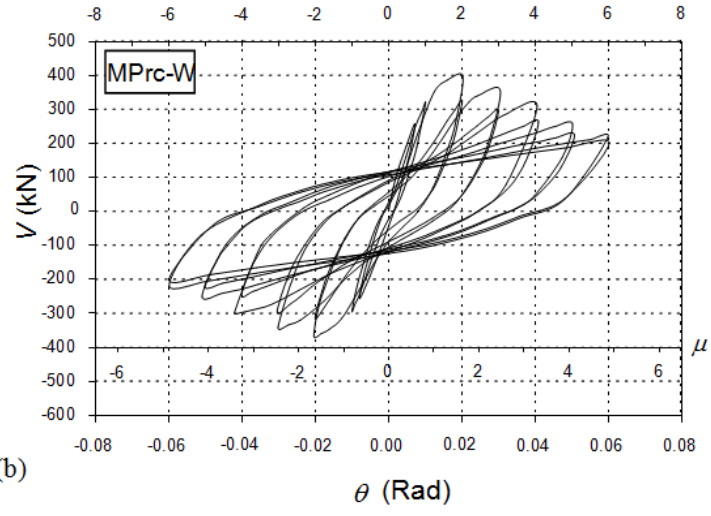

Fig. 8 Comparison of hysteretic loops (a) MPrc-N [17] and (b) MPrc-W [18]

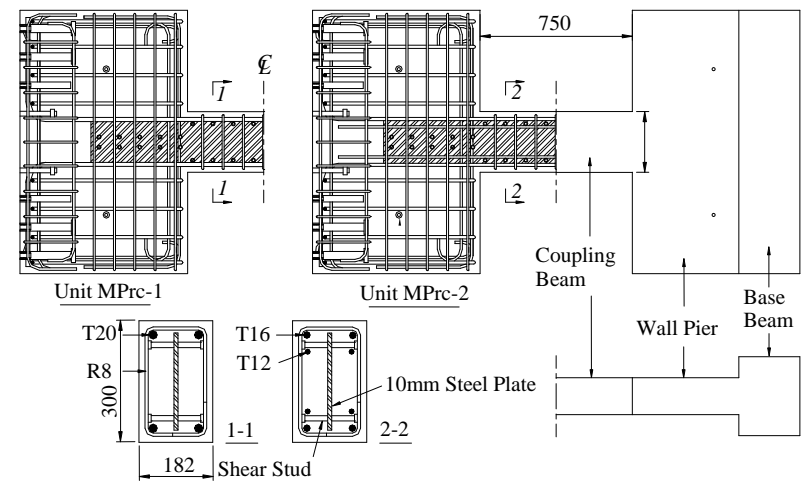

(a)
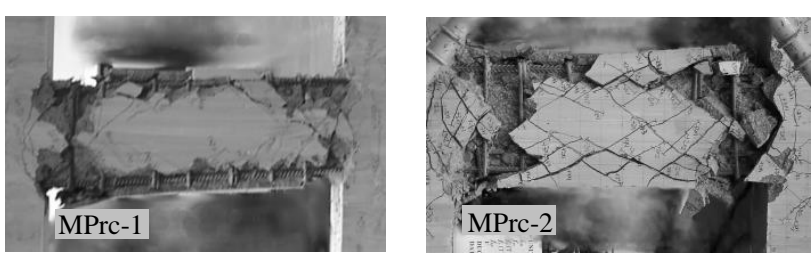

(b)

Fig. 9 PRC coupling beams (a) geometry and details of RC component and (b) failure modes [26] 
Table 1

Summary of experimental results

\begin{tabular}{|c|c|c|c|c|c|}
\hline Span-to-depth ratio & Reference & Unit & Failure Mode & $V_{\max }(\mathrm{kN})$ & $\theta_{\mathrm{u}}(\mathrm{Rad})$ \\
\hline \multirow[t]{6}{*}{2.5} & {$[17]$} & MRc & Flexural shear / Bond-slip & 213 & 0.029 \\
\hline & [17] & MPrc-N & Flexural shear / Bond-slip & 360 & 0.031 \\
\hline & [18] & MPrc-B & Flexural shear / Bond-slip & 408 & 0.048 \\
\hline & [17] & MPrc-W & Flexural shear / Bond-slip & 397 & 0.050 \\
\hline & [16] & MPrc-1 & Flexural shear / Bond-slip & 417 & 0.080 \\
\hline & {$[16]$} & MPrc-2 & Flexural shear & 434 & 0.056 \\
\hline \multirow[t]{3}{*}{1.17} & {$[19]$} & SDRc & Buckling of Bars & 346 & 0.044 \\
\hline & [19] & SPrc-1 & Shear-sliding & 438 & 0.037 \\
\hline & [19] & SPrc-2 & Shear - compression & 474 & 0.041 \\
\hline
\end{tabular}

\section{Conclusions}

Previous experimental and numerical results in the literature are used to discuss the interaction process of RC components and embedded steel plates and the functions of shear studs on PRC coupling beams. Two composite actions are found; one at the wall anchor and the other along the span region of the beam. It is found that the full strength potential of PRC coupling beams is not only affected by the strength of the steel plate and wall anchor but also the reinforcement ratio of the $\mathrm{RC}$ wall piers. The inelastic response of PRC coupling beams is significantly affected by the composite action at the wall anchor. The embedded steel plate can contribute to continuing shear transfer

\section{References}

[1] Tassios T.P., Moretti M. and Bezas A., "On the behavior and ductility of reinforced concrete coupling beams of shear walls", ACI Structural Journal, 93(6), 711-720, 1996

[2] Galano L. and Vignoli A., "Seismic behavior of short coupling beams with different reinforcement layouts", ACI Structural Journal, 97(6), 876-885, 2000.

[3] Breña S.F. and Ihtiyar O., "Performance of conventionally reinforced coupling beams subjected to cyclic loading", Journal of Structural Engineering, 137(6), 665-676, 2011.

[4] Li X., Sun Y.S., Ding B.D. and Xia C.Z., "Cyclic Behavior of Deep RC Coupling Beams with Different Reinforcement Layouts", Journal of Earthquake Engineering, 24(1), 155-174, 2020.

[5] Cheng B. and Su R.K.L., "Numerical studies of deep concrete coupling beams retrofitted with a laterally restrained steel plate", Advances in Structural Engineering, 14(5), 903-915, 2011

[6] Cheng B. and Su R.K.L., "Retrofit of deep concrete coupling beams by a laterally restrained side plate", Journal of Structural Engineering, 137(4), 503-512, 2011.

[7] Cheng B., Su R.K.L., Shi C. and Yang C.T., "Laterally restrained steel plate with stiffeners for seismic retrofitting of concrete coupling beams", Advanced Steel Construction, 12(2), 194-210, 2016

[8] Fortney P.J., Rassati G.A. and Shahrooz B.M., "Investigation on effect of transverse reinforcement on performance of diagonally reinforced coupling beams", ACI Structural Journal, 105(6), 781, 2008.

[9] Harries K.A., Fortney P.J., Shahrooz B.M. and Brienen P.J., "Practical design of diagonally reinforced concrete coupling beams-critical review of ACI 318 requirements", ACI Structural Journal, 102(6), 876-882, 2005.

[10] Chun Y.S. and Chang K.K., "Seismic performance of special reinforced concrete coupling beams with diagonal reinforcement and headed bars", Magazine of Concrete Research, 68(6), 283-290, 2016.

[11] Paulay T. and Binney J.R., "Diagonally reinforced coupling beams of shear walls", ACI Special Publication, SP-42, 579-598, 1974.

[12] Li Y., Jiang H. and Yang T.Y., "Damage Deformation of Flexure-Yielding Steel-Reinforced Concrete Coupling Beams: Experimental and Numerical Investigation", Advances in Civil Engineering, Article ID 7071243, 2019.

[13] Harries K.A., Gong B.N. and Shahrooz B.M., "Behavior and design of reinforced concrete, steel, and steel-concrete coupling beams", Earthquake Spectra, 16, 775-799, 2000.

[14] Lam W.Y., Su R.K.L. and Pam H.J., "Strength and ductility of embedded steel composite coupling beams". Advances in Structural Engineering, 6, 23-35, 2003.

[15] Liao S. and Pimentel B., "Coupling beam types", Structure Magazine, 1, 8-13, 2019.

[16] Lam W.Y., Su R.K.L. and Pam H.J., "Seismic performance of plate reinforced composite coupling beams", Proceedings of the 13th World Conference on Earthquake Engineering, Vancouver, BC Canada, paper no. 316, 1-11, 2004

[17] Lam W.Y., Su R.K.L. and Pam H.J., "Experimental study on embedded steel plate composite coupling beams", Journal of Structural Engineering ASCE, 131, 1294-1302, 2005.

[18] Su R.K.L., Pam H.J. and Lam W.Y., "Effects of shear connectors on plate-reinforced composite coupling beams of short and medium-length spans", Journal of Constructional Steel Research, 62, 178-188, 2006.

[19] Su R.K.L., Lam W.Y. and Pam H.J., "Experimental study of plate-reinforced composite deep coupling beams", The Structural Design of Tall and Special Buildings, 18, 235-257, 2009.

[20] Su R.K.L., Lam W.Y. and Pam H.J., "Behaviour of embedded steel plate in composite coupling beams", Journal of Constructional Steel Research, 64, 1112-1128, 2008.

[21] Lam W.Y., Li L.Z., Su R.K.L. and Pam H.J., "Behavior of plate anchorage in plate-reinforced composite beams", The Scientific world Journal, Article ID 190430, 2013.

[22] Su R.K.L. and Lam W.Y., "A unified design approach for plate-reinforced composite coupling beams", Journal of Constructional Steel Research, 65, 675-686, 2009.

[23] Baldridge S.M., Popp D.R. and Mizue E., "Structural performance on Waikiki Beach", Structural Engineer, 3e, 30-33, 2009. across the beam-wall joints after concrete cracking. Furthermore, the typical shear strength limit, ductility and rotation capacities and damping coefficient of properly designed PRC coupling beams are found to increase in PRC coupling beams with sufficient number of shear connectors in the wall anchors. The equivalent elastic damping coefficient can be increased from around $5 \%$ to $12 \%$ for a ductility factor that has increased from 1.0 to 4.0 . The findings in this paper can be used to enhance the understanding of practitioners on the load-transfer process and capability of PRC coupling beams.

[24] Baldridge S.M., "400 feet, 53 stories: How a structural engineer was able to squeeze as many floors as possible under restrictive height", Structural Engineer, 7, 16-20, 2012.

[25] Mattock A.H. and Gaafar G.H., "Strength of embedded steel sections as brackets", AC Journal, 79(9), 83-93, 1982

[26] Lam W.Y. Plate-Reinforced Composite Coupling Beams-Experimental and Numerical Studies, PhD thesis, The University of Hong Kong, Hong Kong, 2006. 